\title{
Open-Access Knowledge and Economic Growth: An Economic Model
}

\author{
Xiaoqun Zhang ${ }^{1}$ \\ ${ }^{1}$ School of Media and Communication, Bowling Green State University, United States \\ Correpondence: Xiaoqun Zhang, School of Media and Communication, Bowling Green State University, United \\ States. E-mail: xzhang@bgsu.edu
}

Received: November 25, 2013

Accepted: December 31, 2013

Online Published: February 21, 2014

doi:10.5539/ijbm.v9n3p43

URL: http://dx.doi.org/10.5539/ijbm.v9n3p43

\begin{abstract}
The intellectual property (IP) law has been forcefully challenged by scholars and anti-IP movement activists in recent years. The critiques from scholars mainly focused on the enclosure of information and knowledge enforced by IP law. And the activists of anti-IP movements argued for the open access to knowledge to promote creation.

This study proposes an endogenous economic growth model highlighting the role of open-access knowledge in economic growth. The solution of the model shows that the production efficiency of knowledge, the converting efficiency from knowledge products into human capital, and the externality of knowledge products, will have impacts on the economic growth rate. The policy implication of this study is that government's intervention, such as the subsidy to the knowledge production, investment in the open-access knowledge, and regulation on the quality of knowledge products, will have positive effects on economic growth.
\end{abstract}

Keywords: open-access knowledge, economic growth, intellectual property, human capital

\section{Introduction}

Since the middle of 20th century, the rapid development of digital technologies initiated a new round of technology revolution, the so-called "information revolution", and pushed human society move forward to a new era. Daniel Bell (1976) named this new society as "post-industrial society". Manuel Castells (1999) called it as "network society." They both argued that the new society is different from the old one in that the key social structures and activities are organized around electronically processed information. In this new society, the economic development model has changed tremendously because the wealth is created more from information and knowledge than natural resources. In this regard, the economy nowadays is called "knowledge economy" or "knowledge-based economy" (Organization for Economic Co-operation and Development, 1996).

In the knowledge economy, knowledge production and utilization become the major driving force for economic growth. Therefore, many developed countries invest intensively in knowledge production. According to the statistics of Organization for Economic Co-operation and Development (2008), the top spenders of research and development (R\&D) are all developed countries including Sweden (3.73\% of GDP), Japan (3.39\% of GDP) and United States (2.62\% of GDP). At the same time, the intellectual property (IP) law with the aim of "safeguarding creators and other producers of intellectual goods and services" has been strengthened more than ever before (World Intellectual Property Organization, 2003, p. 3). In academia, IP law has become one major research domain of liberal arts and gained support from many scholars from multiple disciplines (the so-called "pro-IP camp"). At the same time, it has become a significant issue in the international trade, especially after the World Trade Organization (WTO) requiring its nation members to implement the Agreement on Trade-Related Aspects of Intellectual Property Rights (TRIPS) in 1994.

On the other hand, an opposite school of thought against IP law (the so-called "anti-IP camp") has become increasingly influential in recent years. This camp includes the critiques of IP law from a number of scholars and multiple movements pushed by thousands of activists, such as free and open source software, free culture, open content, open business, open standards, open licensing, and open educational resources (Mizukami \& Lemos, 2008). Different from the pro-IP camp which argued IP law "promotes investments in knowledge creation and business innovation by establishing exclusive rights to use and sell newly developed technologies, goods, and 
services" (Maskus, 2000, p. 473), the scholars in the anti-IP camp argued that IP law protects the benefits of big companies instead of creators, and it cultivates a "permission culture" which controls creators to get access of the existing knowledge (Lessig, 2004, p. 15). Since knowledge is believed as the driving force for economic growth in the knowledge economy, these two opposing arguments would reach opposing conclusions regarding the role of IP law in economic growth.

Besides the difference in the central argument, the two camps employed different methodologies. Many studies in the pro-IP camp employed economic analysis, whereas most studies in the anti-IP camp relied on intuitive, philosophical, or even historical basis. Bettig (1996) argued that economic analysis is more forceful in the policy making process than other approaches. If the scholars in anti-IP camp employ the economic analysis, the current IP statue either in academia or policy would be more forcefully challenged. This study is such an explorative attempt. In particular, it developed a theoretical model to investigate the role of open-access knowledge in economic growth.

\subsection{The Critiques of IP Law and Anti-IP Movements}

In the era of the information society and knowledge economy, "no area of law has a more pervasive impact than intellectual property." (Shave, 2008a, p. 8) IP law determines the ownership, rights, and the usage of the most important economic asset of this era: the new knowledge. The earliest regulation over IP at the international level was enforced in 1883 with the Paris Convention for the Protection of Industrial Property. The regime of IP has expanded rapidly since then. At present, nearly all countries in the world have joined in this regime and accepted the rules made by the World Intellectual Property Organization (WIPO). The World Trade Organization's efforts on the protection of the intellectual property further reinforced the international commitment to IP law.

Although IP law has achieved the commitments from the governments and gained rhetorical power on society, it has endured many critiques since as early as the 1960s. Many scholars have joined the anti-IP camp over the past decade. Tullock (1967) and Krueger (1974) argued that the IP law is the outcome of the lobby efforts of the powerful market players, and it actually creates legal monopolies and guarantees the benefits of the monopolies. Noble (1977) demonstrated that IP law had been used as the effective tool to cartelize markets in the automobile and steel industries. Likewise, Rothbard (1993) argued that IP law erects the competitive barriers and thus is detrimental to the free market competition and consumer's benefits. Other scholars criticized IP law from the perspectives beyond market efficiency. For example, Noble (1977) stated that IP law prevents the diffusion of technologies throughout the market. Peng (1990) argued that IP law prohibits the diffusion of innovations from the developed countries to developing countries. Maskus and Reichman (2004) held that IP law reduces the public good and social welfare that governments provide to the public. Drahos and Braithwaite (2002) and Lessig (2004) believed that IP law forces the enclosure of information and knowledge and hence impede the creation of new information and knowledge. In regard of the topic of this study, the most significant critique comes from the scholars who challenged the role of IP law in economic growth. IP law has been considered as the incentive for innovations and economic growth by pro-IP camp (Commission on Intellectual Property Rights, 2002; Grandstand, 2006). And this argument has widely been taken as the assumption by the policy-makers in both the developed and developing countries (Shaver, 2008a). Nevertheless, some scholars in the anti-IP camp challenged this assumption. For example, Gallin and Scotchmer (2002) and Maskus (2000) argued that IP law is not the necessarily incentive for creation, and hence, not effectively promotes economic growth.

Along with these scholarly critiques, many activists have engaged in the anti-IP movements. Richard Stallman launched the Free Software Foundation to enhance "the users' freedom to run, copy, distribute, study, change, and improve the software" (Stallman, 2002, p. 43). The free software movement has achieved international status as long as more and more free software projects accumulated. In the late 1990s, another camp of the movement - open source movement - established with the different doctrines from the initial free software movement. This movement shifts the emphasis from the "licensing models" to "business models" and expands the use of free software from hackers to ordinary users (Mizukami \& Lemos, 2008). The free culture movement, led by Lawrence Lessig, expands the strategies of free software movement to the broader realm of cultural production. Lawrence Lessig created the well-known website "Creative Commons" which lists the licenses that permit sharing and offers the search services for the creative-commons-licensed productions. Based on the critically review of IP law, he argued that the IP law creates a "permission culture" (Lessig, 2004, xiv), a culture in which creators get to create only with the permission of creators from the past, and a culture that impedes the free exchange of ideas and prohibits innovations. Lessig (2004) developed the concept of "free culture", a culture that "guarantees that follow-on creators and innovators remain as free as possible from the control of the past" (Lessig, 2004, p. 15). With the same philosophy and strategies of the free software movement and free 
culture movement, many activists have engaged in the open access to knowledge movement. In 2004, these activists successfully prompted a call for a new development agenda of WIPO, resulting in the acceptance of the access to knowledge as one of the goals of WIPO (World Intellectual Property Organization, 2007, Recommendation 19).

\section{Two Economic Growth Models}

Benkler (2005) and Shaver (2008b) argued that the open access to knowledge would promote broad economic benefits for the public. Follow this argument, as well as the critique of the negative influence of IP law on the economic development (e.g., Gallin \& Scotchmer; 2002; Maskus, 2000; Shaver, 2008a), this study investigated the positive influence of open-access knowledge on economic growth. Economic growth refers to the constant growth of average output per capita (Kuznets, 1991). Economic growth is one of the major research domains of macroeconomics. In this domain, the endogenous growth theory has become the dominant theory since the 1980s. Two models proposed by Romer (1990) and Lucas (1988) laid the foundation for the development of this theory.

Romer (1990) breaks through the assumption of exogenous technological change, and reveals the mechanism of endogenous technological change driven by the reasonable decisions of market players who pursuit the maximum profits. In this model, the economy is constituted by three sectors: the research sector which uses human capital and existing stock of knowledge to produce new knowledge; the intermediate goods sector which uses the designs of the research sector to produce equipment (producer durables) that used in the final goods production process, and the final sector which uses labor, human capital, and equipment to produce final output. The production function of final sector is:

$$
Y\left(H_{Y}, L, x\right)=H_{Y}^{\alpha} L^{\beta} \sum_{i=1}^{\infty} x_{i}^{1-\alpha-\beta} d i
$$

Where Hy denotes the human capital input of final sector, $\mathrm{L}$ denotes the labor input of final sector, $x_{i}$ denotes the equipment.

The knowledge production dynamic function of the research sector is

$$
\dot{A}=\delta H_{A} A
$$

Where $\dot{A}$ denotes the new knowledge production rate, $\mathrm{H}_{\mathrm{A}}$ denotes the human capital input in the research sector, $A$ denotes the existing knowledge stock.

This model provides an explanation for the endogenous knowledge production. The new knowledge production is the result of the rational decisions of investors. The solution of this model demonstrates that the economic growth rate is the increasing function of human capital, and independent of the labor number. Moreover, the government's policy, such as the subsidy for R\&D and education, will increase the economic growth rate.

Lucas (1988) highlights the externality of human capital. Human capital is an important concept in the economic growth theory. It theorizes the intelligence, knowledge, techniques and health the laborers possess (Becker, Murphy, \& Taura, 1990; Schultz, 1961). Lucas (1988) argues that the externality of human capital has the characteristic of increasing return because it contributes to the increase of all production factors. In this model, the economy has two sectors: the material good producing sector and human capital producing sector. The production function of the material good producing sector is as following:

$$
Y=A K^{\beta}(u N h)^{1-\beta} h_{a}^{\gamma}
$$

Where $A$ denotes the exogenous technology, $K$ denotes capital, $N$ denotes labor, $h$ denotes human capital, $h_{a}$ denotes average human capital, $\gamma$ denotes the externality of human capital.

The human capital production function is:

$$
\dot{h}=h \delta(1-u)
$$

Where parameter $\delta>0$, and $u$ denotes the input time of human capital production.

In the balance growth path of the solution, the growth of human capital depends on the time input for human capital. The economic growth rate relates to the growth rate of labor. However even when the growth rate of labor is zero, there is still a positive growth rate of economic growth because of the externality of human capital. 


\subsection{Critical Review of the Two Models from an Open-Access Knowledge Perspective}

IP law plays a crucial role in Romer (1990) model because the monopoly power which is granted by IP law provides the necessary incentive for the market players to engage in the R\&D activities. In this sense, Romer's model provides justification for IP regulation. However, this model has an important assumption: anyone engaged in research has free access to the entire stock of knowledge (Romer, p. 83). In fact, IP law denies free access to the existing knowledge. Furthermore, this model emphasizes the technology progress embodied in manufacture equipment, neglecting the change of the global division of labor. The manufacture industries have been shifted from the developed countries to developing countries, especially large ones such as China and India. They are losing their shares in the nation's economy and no longer act as the driving engine for the economic growth in many developed countries. On the other hand, the creative industries are becoming increasingly important in these countries. For example, the U.S. creative industries contributed more to the nation's economy and employed more workers than any single manufacturing sector (Shapiro, p. 30).

In the process of creative production, human capital has more value than physical capital, and the entry barrier is lower than other processes of production (Carson, 2009). In other words, the output mainly depends on the human capital instead of equipment. Thus, it is reasonable to argue that in the economy that heavily relies on the creative production, economic growth is driven by the enhancement of human capital rather than technological change in the manufacture equipment. Lucas (1988) explains the role of human capital in economic growth. However, it emphasizes the time input factor in the human capital accumulation and overlooks other factors. Time spent on learning is an important factor for human capital but it is not the only one. Other factors, especially the accessibility of knowledge, are also indispensable. As criticized by most anti-IP scholars, IP law acts as the obstacle to the access of knowledge (e.g., Drahos, \& Braithwaite, 2002; Lessig, 2004). The anti-IP camp advocates the freedom of sharing knowledge and empowerment of creators and readers (e.g., Lessig, 2004; Litman, 2007, 2010; Stallman, 2002). This study took this argument as the foundation to build a new economic growth model.

\subsection{A New Economic Growth Model Based on Open-Access Knowledge}

Following Lucus (1988), the proposed model also takes human capital as the key driving force for economic growth. However, this model describes a different mechanism through which human capital accumulation depends on the amount of knowledge products. In this model, the economy is constituted by two sectors: final goods production sector and knowledge production sector. The final goods sector is a free competition market in which innumerable same firms produce same quality products. The output of this sector is denoted by $Y$. People in this economy are divided into two groups: one group consists of the researchers whose job is to generate new knowledge; another group consists of the laborers who produce final goods. The human capital depends on the knowledge products available to labor. The production function of the final goods sector is the same as that of Lucas (1988) model:

$$
\mathrm{Y}=\mathrm{AK}^{\alpha}\left(\mathrm{hL}_{\mathrm{Y}}\right)^{1-\alpha}
$$

Where $A$ denotes the comprehensive effect of other factors except capital, labor and human capital, $K$ denotes capital, $h$ denotes human capital, $\mathrm{L}_{\mathrm{Y}}$ denotes the labors in the final goods production sector, $\alpha$ denotes the elasticity of capital, $0<\alpha<1$.

For the purpose of simplification, this model assumes that the depreciation rate of capital is zero, thus the capital accumulation function is:

$$
\dot{\mathrm{K}}=\mathrm{Y}-\mathrm{C}=\mathrm{AK}^{\alpha}\left(\mathrm{hL}_{\mathrm{Y}}\right)^{1-\alpha}-\mathrm{C}
$$

The total amount of labor is assumed constant:

$$
\mathrm{L}_{\mathrm{Y}}+\mathrm{L}_{\mathrm{M}}=\mathrm{L}
$$

Where $\mathrm{L}_{\mathrm{M}}$ denotes the labors in the knowledge production sector.

Set $\mathrm{L}_{\mathrm{Y}} / \mathrm{L}=\mathrm{u}$, thus $\mathrm{L}_{\mathrm{M}} / \mathrm{L}=1-\mathrm{u}$

The capital accumulation function equation (4) can be derived by equation (2) and (3): 


$$
\dot{\mathrm{K}}=\mathrm{AK}^{\alpha}(\mathrm{hu})^{1-\alpha}-\mathrm{C}
$$

The human capital is assumed as the function of the education level and the knowledge products a labor gets.

$$
\mathrm{h}(\mathrm{t})=\mu \mathrm{e}^{\varphi \ell} \mathrm{MK}(\mathrm{t})^{\phi} \mathrm{mk}(\mathrm{t})^{\lambda}
$$

Where $h(t)$ denotes the human capital level, $\ell$ denotes the average education level of labor, $M K(t)$ denotes the knowledge products, $\phi$ is the parameter which has two cases: $1 \geq \phi>0$ or $\phi<0$. The case of $1 \geq \phi>0$ denotes that the knowledge product has positive effect on human capital, where as $\phi<0$ denotes the negative effect. The variable $\mathrm{mk}(\mathrm{t})$ denotes the externality of knowledge. When the system is in equilibrium, $\mathrm{mk}(\mathrm{t})=\mathrm{MK}(\mathrm{t})$. Parameter $\lambda>0$ denotes that the knowledge has positive externality because it has the characteristic of non-excludability.

Another group of people $\left(\mathrm{L}_{\mathrm{M}}\right)$ are researchers who are engaged in knowledge production. The knowledge production function is the same as that in Romer (1990) model

$$
\dot{\mathrm{MK}}=\xi \mathrm{L}_{\mathrm{M}} \mathrm{MK}
$$

The human capital accumulation dynamic function can be deducted by equation (5) and (6)

$$
\dot{\mathrm{h}}=\xi(\phi+\lambda)(1-\mathrm{u}) \mathrm{h}
$$

The preference function of representative consumer is

$$
\int_{0}^{\infty} \frac{\mathrm{c}^{1-\sigma}-1}{1-\sigma} \mathrm{e}^{-\rho \mathrm{t}} \mathrm{dt}
$$

Where $\sigma \geq 0, \rho>0 ; 1 / \sigma$ denotes inter-temporal substitute elasticity, $\rho$ denotes the time preference rate, C denotes consumption. On the equilibrium growth path:

$$
\frac{\dot{\mathrm{c}}}{\mathrm{c}}=\frac{\mathrm{r}-\rho}{\sigma}
$$

The knowledge products are assumed to be public goods which have the characteristics of non-excludability and non-rivalry. This assumption is congruent with the central thesis of the anti-IP camp. Even though the scholars in this camp think of "free" as in "free speech", not as in "free beer" (Stallman, 2002, p. 43), they advocate the freedom to redistribute copies either gratis or for a fee (p. 20). This freedom will break the monopoly of knowledge products and render a marketplace with the free exchange of knowledge. On the other hand, the scholars of this school advocate the subsidy of government for the access to knowledge (Landers \& Posner, 2003). With the government's intervention, the final equilibrium of the economic growth rate and the distribution of labors between two sectors are equal to the solution of a social planner problem. The dynamic programming model is described as:

$$
\max \int_{0}^{\infty} \frac{\mathrm{C}^{1-\sigma}}{1-\sigma} \mathrm{e}^{-\rho \mathrm{t}} \mathrm{dt}
$$

s.t:

$$
\dot{\mathrm{K}}=\mathrm{AK}^{\alpha}(\mathrm{hu})^{1-\alpha}-\mathrm{C}
$$

$$
\dot{\mathrm{h}}=\xi(\phi+\lambda)(1-\mathrm{u}) \mathrm{h}
$$

Where $K(0)$ and $h(0)$ are preset.

\subsection{The Solution of the Economic Model}

Dynamic optimization method was used to deduce the solution of the proposed economic model. This method has been employed by economists to solve the problem for an economic agent who needs to allocate resources 
between the consumption commodities and capital commodities over time. The following procedure shows the steps of the deduction of the solution.

In order to find the solution of the dynamic programming, Hamilton is given

$$
\mathrm{H}(\mathrm{C}, \mathrm{u}, \mathrm{K}, \mathrm{h})=\frac{\mathrm{C}^{1-\sigma}}{1-\sigma}+v\left[\mathrm{AK}^{\alpha}(\mathrm{hu})^{1-\alpha}-\mathrm{C}\right]+\mu[(\phi+\lambda) \xi(1-\mathrm{u})] \mathrm{h}
$$

F. O. C:

$$
\begin{gathered}
\frac{\partial \mathrm{H}}{\partial \mathrm{C}}=0 \Rightarrow \mathrm{C}^{-\sigma}=v \\
\frac{\partial \mathrm{H}}{\partial \mathrm{u}}=0 \\
\Rightarrow(1-\alpha) v \mathrm{AK}^{\alpha} \mathrm{h}^{(1-\alpha)} \mathrm{u}^{-\alpha}-\mu \xi \mathrm{h}(\phi+\lambda)=0 \\
\Rightarrow \frac{\mu}{v}=\frac{\mathrm{A}}{(\phi+\lambda) \xi}(1-\alpha) \mathrm{u}^{-\alpha} \omega^{\alpha} \\
\dot{v}=\rho v-\frac{\partial \mathrm{H}}{\partial \mathrm{K}}=\rho v-\alpha v \mathrm{Au}^{1-\alpha} \omega^{-(1-\alpha)} \\
\Rightarrow \frac{v}{v}=\rho-\alpha \mathrm{Au}^{1-\alpha} \omega^{-(1-\alpha)} \\
\dot{\mu}=\rho \mu-\frac{\partial \mathrm{H}}{\partial \mathrm{h}}=\rho \mu-(1-\alpha) v \mathrm{AK}{ }^{\alpha}(\mathrm{hu})^{-\alpha} \mathrm{u}-\mu[(\phi+\lambda) \xi(1-\mathrm{u})] \\
\dot{\mu}=\rho-\left(\frac{v}{\mu}\right)(1-\alpha) \mathrm{A} \omega^{\alpha} \mathrm{u}^{1-\alpha}-(\phi+\lambda) \xi(1-\mathrm{u})
\end{gathered}
$$

The transversality condition is:

$$
\begin{aligned}
& \lim _{\mathrm{t} \rightarrow \infty} v \mathrm{Ke}^{-\rho \mathrm{t}}=0 \\
& \lim _{\mathrm{t} \rightarrow \infty} \mu \mathrm{he}^{-\rho \mathrm{t}}=0
\end{aligned}
$$

On the balanced growth path, the growth rate of every variable and interest rate are constant. The author defines: $\omega=\frac{\mathrm{K}}{\mathrm{h}}$ and $\chi=\frac{\mathrm{C}}{\mathrm{K}}$. The growth rates of $K\left(\gamma_{\mathrm{K}}\right)$ and $h\left(\gamma_{\mathrm{h}}\right)$ are obtained by equation (4) and (7)

$$
\begin{aligned}
& \gamma_{\mathrm{K}}=\mathrm{Au}^{1-\alpha} \omega^{-(1-\alpha)}-\chi \\
& \gamma_{\mathrm{h}}=(\phi+\lambda) \xi(1-\mathrm{u})
\end{aligned}
$$

The growth rate of $\omega$ is:

$$
\gamma_{\omega}=\gamma_{\mathrm{K}}-\gamma_{\mathrm{h}}=\mathrm{Au}^{1-\alpha} \omega^{-(1-\alpha)}-\chi-(\phi+\lambda) \xi(1-\mathrm{u})
$$

The growth rate of $\chi$ is: 


$$
\gamma_{\chi}=\gamma_{\mathrm{C}}-\gamma_{\mathrm{K}}=\left(\frac{\alpha-\sigma}{\sigma}\right) \mathrm{Au}^{1-\alpha} \omega^{-(1-\alpha)}+\chi-\frac{\rho}{\sigma}
$$

The growth rate of $u$ is:

$$
\gamma_{\mathrm{u}}=\frac{\dot{\mathrm{u}}}{\mathrm{u}}=\frac{1-\alpha}{\alpha}(\xi(\phi+\lambda)+\mathrm{g})+(\phi+\lambda) \xi \mathrm{u}-\chi
$$

Equation (15), (16) and (17) constitute a differential equation

$$
\begin{gathered}
\gamma_{\omega}=\mathrm{Au}^{1-\alpha} \omega^{-(1-\alpha)}-\chi-(\phi+\lambda) \xi(1-\mathrm{u}) \\
\gamma_{\chi}=\left(\frac{\alpha-\sigma}{\sigma}\right) \mathrm{Au}^{1-\alpha} \omega^{-(1-\alpha)}+\chi-\frac{\rho}{\sigma} \\
\gamma_{\mathrm{u}}=\frac{1-\alpha}{\alpha}(\phi+\lambda) \xi+(\phi+\lambda) \xi \mathrm{u}-\chi
\end{gathered}
$$

In equilibrium solution of the differential equation, these three variables are constant. That is $\dot{\mathrm{u}}=0, \dot{\omega}=0, \dot{\chi}=0$. Thus the following three equations are obtained

$$
\begin{gathered}
\mathrm{Au}^{1-\alpha} \omega^{-(1-\alpha)}-\chi-(\phi+\lambda) \xi(1-\mathrm{u})=0 \\
\left(\frac{\alpha-\sigma}{\sigma}\right) \mathrm{Au}^{1-\alpha} \omega^{-(1-\alpha)}+\chi-\frac{\rho}{\sigma}=0 \\
\frac{1-\alpha}{\alpha}(\phi+\lambda) \xi+(\phi+\lambda) \xi \mathrm{u}-\chi=0
\end{gathered}
$$

The solution of these three equations gives the values of $\mathrm{u}, \chi$ and $\omega$

$$
\begin{gathered}
\mathrm{u}^{*}=\frac{\rho-(1-\sigma)(\phi+\lambda) \xi}{\sigma(\phi+\lambda) \xi} \\
\chi^{*}=\left(\frac{1}{\alpha}-\frac{1}{\sigma}\right)(\phi+\lambda) \xi+\frac{\rho}{\sigma} \\
\omega^{*}=\left(\frac{\alpha \mathrm{A}}{(\phi+\lambda) \xi}\right)^{\frac{1}{1-\alpha}}\left(\frac{\rho-(1-\sigma)(\phi+\lambda) \xi}{\sigma(\phi+\lambda) \xi}\right)
\end{gathered}
$$

The interest rate in equilibrium is:

$$
\mathrm{r}^{*}=(\phi+\lambda) \xi
$$

The growth rate of capital is:

$$
\frac{\dot{\mathrm{C}}}{\mathrm{C}}=\frac{1}{\sigma}(\phi \xi-\rho)
$$

In equilibrium $\mathrm{u}, \omega$, and $\chi$ are constant. From the definitions of $\omega$ and $\chi$, the following equation is obtained:

$$
\frac{\dot{\mathrm{C}}}{\mathrm{C}}=\frac{\dot{\mathrm{K}}}{\mathrm{K}}=\frac{\dot{\mathrm{h}}}{\mathrm{h}}
$$


Furthermore, all variables have same growth rate:

$$
\gamma^{*}=\frac{\dot{\mathrm{C}}}{\mathrm{C}}=\frac{\dot{\mathrm{K}}}{\mathrm{K}}=\frac{\dot{\mathrm{Y}}}{\mathrm{Y}}=\frac{\dot{\mathrm{h}}}{\mathrm{h}}=\frac{1}{\sigma}((\phi+\lambda) \xi-\rho)
$$

Finally, the capital $(K)$ and output of the economy $(Y)$ on the balanced growth path are obtained:

$$
\begin{aligned}
& \mathrm{K}(\mathrm{t})^{*}=\mathrm{K}(0) \mathrm{e}^{\frac{1}{\sigma}((\phi+\lambda) \xi-\rho) \mathrm{t}} \\
& \mathrm{Y}(\mathrm{t})^{*}=\frac{1}{\alpha}(\phi+\lambda) \xi \mathrm{K}(0) \mathrm{e}^{\frac{1}{\sigma}((\phi+\lambda) \xi-\rho) \mathrm{t}}
\end{aligned}
$$

\section{Conclusion and Discussion}

The balanced growth path solution of the proposed model shows that the equilibrium growth rate of the economy depends on the parameters of the model: $\sigma, \rho, \lambda, \zeta, \phi$. Two of these five parameters, $\sigma$ and $\rho$, are parameters of the utility function, where $1 / \sigma$ is the inter-temporal substitute elasticity, and $\rho$ denotes the time preference rate. These two parameters have no any implication for this study. The implications come from the other three parameters. $\lambda$ denotes the externality of knowledge products. The higher value of $\lambda$ is, the higher the externality of knowledge products is. $\zeta$ is the parameter of knowledge production function denoting the production efficiency. The higher value of $\zeta$ is, the higher the knowledge production efficiency is. $\phi$ denotes the converting efficiency of knowledge into human capital. The higher value of $\phi$ is, the higher the converting efficiency is. The solution of the proposed model shows that when these three parameters increase, the economic growth rate will increase.

The proposed model and its solution have the implications on the policies that government can implement to promote economic growth. First of all, this model is based on the assumption that knowledge products are public goods. Boyle (2008) argued that knowledge should be "the public domain" or "the commons" (p. 38). That is, knowledge should be open to the public and citizens should have the right to access the advancement of knowledge. This right was stated as one of the basic human rights by the Universal Declaration of Human Rights. However, the public good market has the free-rider problem and renders market failure (Clarke, 1980). Thus, government has the responsibility to provide public goods for the public. In regard of the knowledge goods, the investment on public library and other open resources of knowledge is one of the major public policies that government implements to supply open-access knowledge to the public. The more people get the open access to knowledge, the higher the externality of knowledge products is, and then, the higher economic growth rate will be attained. Nevertheless, government can only supply a portion of open-access knowledge to the public. Many knowledge products are monopolized by big market player and not open to the public due to the IP regulation. This scenario has been dramatically changed since the advent of the Internet. With the explosion of open content on the Internet, the scale of open-access knowledge has been tremendously enhanced. Most of the anti-IP movements, such as free software movement, free culture movement, and open access publishing movement, are empowered by the Internet technology.

The solution of the proposed model also shows that government can promote economic growth by implementing other policies. For example, the subsidy for the knowledge production will increase the knowledge production efficiency. The regulation on the quality of knowledge production will influence the converting efficiency from knowledge products to human capital. These policies will also have positive effects on the economic growth rate.

Another fundamental assumption of the proposed model is: the more knowledge products a labor gets, the higher human capital he/she will possess. This assumption overlooks people's motivation and capacity of learning. As a matter of fact, learning is an unpleasant activity for many people. They do not learn even though they have a great amount of knowledge resources. Thus, the more knowledge resources do not necessarily result in the higher human capital level. Nevertheless, this assumption is derived from one of the fundamental assumption of economics: humans are rational so that they pursue the maximum benefits for themselves. In the information society and knowledge economy, the higher human capital will bring about more benefits. Hence, the assumption of this model is justified by the rationality assumption of humans.

This study also has shortcomings in other aspects. First, the proposed model overlooks the function of market players in the knowledge production. In fact, most $R \& D$ activities are invested by the companies which take the 
knowledge products as private goods rather than public goods. Second, it has the implication on the government's regulation on the quality of knowledge products, but not defines that quality. This kind of regulation must relate to the content of knowledge products, and then, would contradict the freedom of speech enshrined in some developed countries, such as U.S. Third, this study uses the education level as an indicator of learning capacity, and thus, simplifies the complicated process of learning. Finally, the proposed model overlooks the international flow of knowledge. Actually, people around the world now enjoy the knowledge stock of the whole world instead of the only knowledge generated within the national border. The Internet promotes the global knowledge flow with an unexpectedly accelerating speed. Many studies demonstrated that the rapid progress of the communication technology has significant influence on economic growth (e.g., Holt \& Jamison, 2009; Koutroumpis, 2009). The findings of these studies should be integrated in this study to further explore the influence of the Internet on the complex relationship between open-access knowledge and economic growth.

\section{References}

Becker, S. G., Murphy, M. K., \& Tamura, R. (1990). Human capital, fertility, and economic growth. Journal of Political Economy, 98, 12-37. http://dx.doi.org/10.1086/261723

Bell, D. (1976). The coming of post-industrial society. New York: Basic Books.

Benkler, Y. (2006). The wealth of networks: How social production transforms markets and freedom. New Haven/London: Yale University Press.

Bettig, V. R. (1996). Copy-righting culture: the political economy of intellectual property. Oxford, U.K.: Westview Press.

Boyle, J. (2008). The public domain: Enclosing the commons of the mind. New Haven: Yale University Press.

Carson, K. A. (2009). Intellectual property: A libertarian critique. Retrieved from http://c4ss.org/wp-content/uploads/2009/05/intellectual-property-a-libertarian-critique.pdf

Castells, M. (1999). The information age: Economy, society and culture. Oxford, UK: Blackwell.

Clarke, H. E. (1980). Demand revelation and the provision of public goods. Cambridge, Massachusetts: Ballinger Publishing Company.

Commission on Intellectual Property Rights (CIPR). (2002). Integrating intellectual property rights and development policy: Report of the commission on intellectual property rights. Retrieved from: $\mathrm{http}: / /$ www.iprcommission.org/graphic/documents/final_report.htm

Drahos, P., \& Braithwaite, J. (2002). Information feudalism: Who owns the knowledge economy? London: Earthscan.

Gallini, N., \& Scotchmer, S. (2002). Intellectual property: when is it the best incentive system? In Jaffe, A. B., Lerner, J., \& Stern, S. (Eds.), Innovation Policy and the Economy (vol. 2). Cambridge Massachusetts: MIT Press.

Grandstand, O. (2006). Innovation and intellectual property rights. In Fagerberg, J., Mowery, D. C., \& Nelson, R. R. (Eds.), The Oxford handbook of innovation (pp. 266-290). Oxford University Press. http://dx.doi.org/10.1093/oxfordhb/9780199286805.003.0010

Holt, L., \& Jamison, M. (2009). Broadband and contribution to economic growth: Lessons from the US experience. Telecommunications Policy, 33, 575-581. http://dx.doi.org/10.1016/j.telpol.2009.08.008

Koutroumpis, P. (2009.) The economic impact of broadband on growth a simultaneous approach. Telecommunications Policy, 33, 471-485. http://dx.doi.org/10.1016/j.telpol.2009.07.004

Krueger, A. (1974). The political economy of the rent-seeking society. The American Economic Review, 64(3), 291-203.

Kuznets, S. S. (1991). Modern economic growth. Beijing, China: Beijing Economic Institute Press.

Landers, M. W., \& Posner, A. R. (2003). The economic structure of intellectual property law. Cambridge, Massachusetts: The Belknap Press.

Lessig, L. (2004). Free culture: the nature and future of creativity. New York: The Penguin Press

Litman, J. (2007). The economics of open access law publishing. Retrieved from http://www-personal.umich.edu/ jdlitman/ 
Litman, J. (2010). Real copyright reform: 96 Iowa Law Review. Retrieved from http://www-personal.umich.edu/ jdlitman/

Lucas, E. R. (1988). On the mechanics of economic development. Journal of Monetary Economics, 22, 3-42. http://dx.doi.org/10.1016/0304-3932(88)90168-7

Maskus, E. K. (2000). Intellectual property rights and economic development. Journal of International Law, $32(2), 471-506$.

Maskus, K. E., \& Reichman, J. H. (2004). The globalization of private knowledge goods and the privatization of global public goods. Journal of International Economic Law, 7(2), 279-320. http://dx.doi.org/10.1093/jiel/7.2.279

Mizukami, N. P., \& Lemos, R. (2008). From free software to free culture: The emergence of open business. In Shave, L. (Ed.), Access to knowledge in Brazil: New research on intellectual property and development (pp. 25-63). New Haven, CT: Information Society Project.

Noble, D. F. (1977). America by design: Science, technology, and the rise of corporate Capitalism. New York: Alfred A. Knopf.

Organization for Economic Co-operation and Development (OECD). (1996). The knowledge-based economy. Retrieved from http://www.oecd.org/dataoecd/51/8/1913021.pdf

Organization for Economic Co-operation and Development (OECD). (2008). Science and innovation: Country notes. Retrieved from http://www.oecd.org/dataoecd/17/53/41558958.pdf

Peng, M. K. K. (1990). The Uruguay round and third world sovereignty. Penang, Malaysia: Third World Network.

Romer, M. P. (1990). Endogenous technological change. Journal of Political Economy, 98(5), 71-102. http://dx.doi.org/10.1086/261725

Rothbard, M. N. (1993). Man, economy, and state: A treatise on economic principles. Auburn, Ala: The Ludwig von Mises Institute.

Schultz, W. T. (1961). Investment in human capital. American Economic Review, 51, 1-17.

Shapiro, M. (2003). The International Copyright System. In Lee B. Becker \& T. Vlad (Eds.), Copyright and consequence: Central European and U.S perspective (pp. 15-32). Cresskill, NJ: Hampton Press.

Shaver, L. (2008a). Access to knowledge in Brazil: New research on intellectual property and development. New Haven, CT: Information Society Project.

Shaver, L. (2008b). Defining and measuring A2K: A blueprint for an index of access to knowledge. A Journal of Law and Policy for the Information Society, 4(2), 235-272.

Stallman, M. R. (2002). Free software, free society: Selected essays of Richard M. Stallman. Retrieved from http://freeculture.wikispaces.com/file/view/stallman.pdf

Tullokc, G. (1967). The welfare costs of tariffs, monopolies and theft. Western Economic Journal, 5, 224-232.

World Intellectual Property Organization (WIPO). (2003). WIPO intellectual property handbook: Policy, Law and Use. Retrieved from http://www.wipo.int/export/sites/www/about-ip/en/iprm/pdf/ch1.pdf

World Intellectual Property Organization (WIPO). (2007). The 45 adopted recommendations under the WIPO development agenda. Retrieved from http://www.wipo.int/ip-development/en/agenda/reommendations.html

\section{Copyrights}

Copyright for this article is retained by the author(s), with first publication rights granted to the journal.

This is an open-access article distributed under the terms and conditions of the Creative Commons Attribution license (http://creativecommons.org/licenses/by/3.0/). 